Im „Journal Club" werden Originalarbeiten aus der internationalen Fachliteratur referiert und kommentiert.

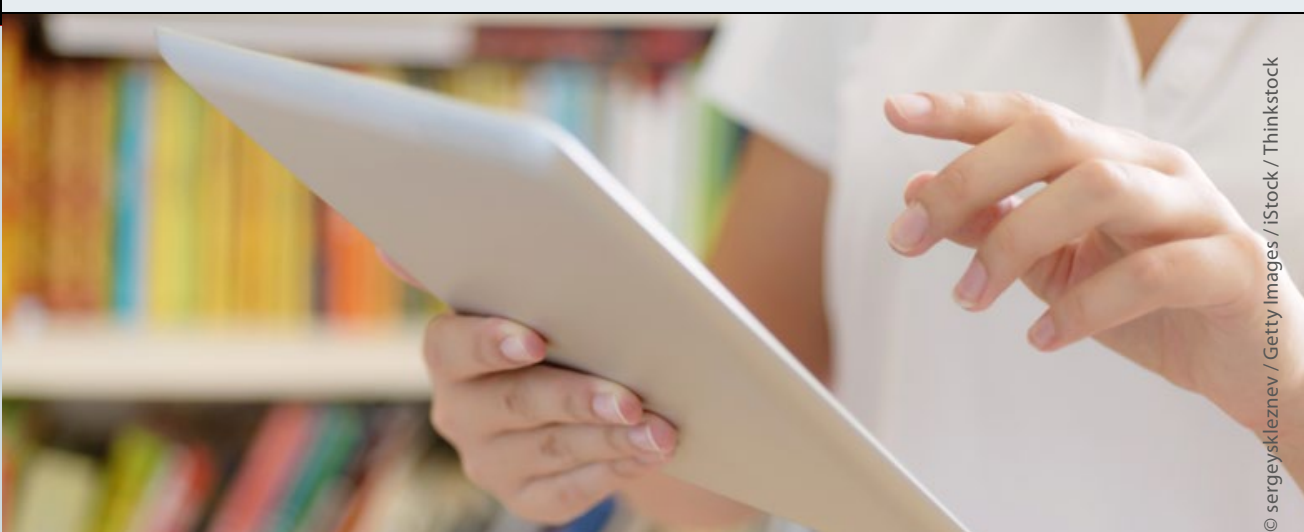

\section{Nykturie: Kalte Wohnung führt zu nächtlichem Harndrang}

\author{
Wenn Senioren in kalten Wohnräumen leben, schlägt ihnen dies während \\ der Nacht offenbar auf die Blase. Möglicherweise müsste man nur die \\ Heizungen aufdrehen, um die Nykturieprävalenz zu senken, meinen die \\ Autoren einer japanischen Studie.
}

$\mathrm{N}$ ykturie bei älteren Menschen ist ein altbekanntes Phänomen. Viele Senioren müssen in der Nacht mindestens zweimal raus. Dadurch wird allerdings nicht nur die wertvolle Nachtruhe gestört. Studien zufolge vergrößert sich mit den nächtlichen Toilettengängen auch die Gefahr von Stürzen und Frakturen und von Depressionen, und auch das Mortalitätsrisiko bei Patienten mit koronarer Herzkrankheit sowie die Gesamtsterblichkeitsrate nehmen zu.

In epidemiologischen Studien hat sich gezeigt, dass Menschen eher im Winter als im Sommer über Nykturie berichten. Deshalb haben Keigo Saeki und Kollegen nun im Rahmen einer Querschnittstudie untersucht, ob Personen ab 60 Jahren nachts häufiger zur Toilette müs-

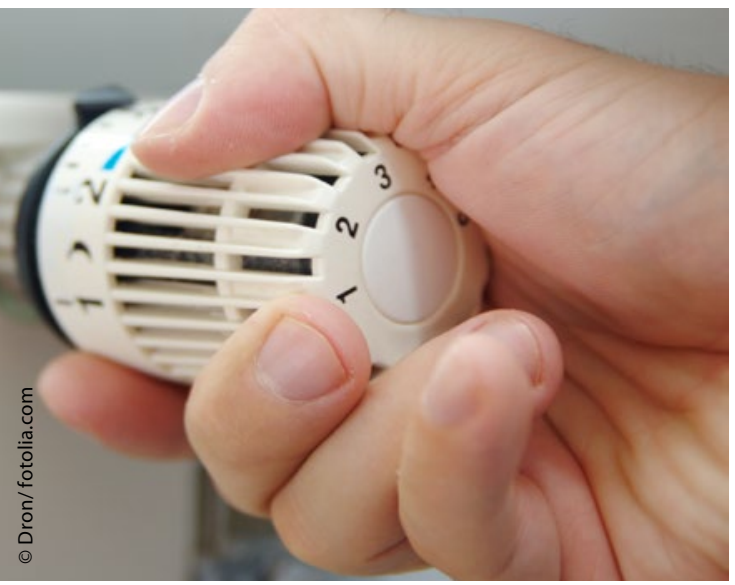

sen, wenn die Wohnräume kalt sind. Hierzu wurde über 48 Stunden die Temperatur in Wohn- und Schlafräumen von 1.065 Senioren im mittleren Alter von 71,9 Jahren gemessen und die Urinausscheidung per Urintagebuch beziehungsweise durch nächtliches Urinsammeln dokumentiert. Fast jeder dritte Studienteilnehmer suchte in der Nacht mindestens zweimal die Toilette auf, und zwar unabhängig von den Jahreszeiten.

\section{Nykturie-Prävalenz durch Heizen senken}

Tatsächlich fanden Saeki und Kollegen signifikante Zusammenhänge zwischen der Wohnraumtemperatur am Tag und der Häufigkeit der Toilettengänge in der Nacht: Eine Absenkung um $1^{\circ} \mathrm{C}$ ging mit einer Odds Ratio (OR) für die Nykturie von 1,095 einher. Diese gesteigerte Häufigkeit nächtlicher Toilettenbesuche war unabhängig von der Außentemperatur beziehungsweise der Jahreszeit sowie anderen Störfaktoren (Alter, Geschlecht, BMI, Alkoholkonsum, Rauchen). Auch Komorbiditäten wie Diabetes oder eine renale Dysfunktion sowie bestimmte Medikamente wie Kalziumkanalblocker, Diuretika oder Schlafmittel, der sozioökonomische Status, der nächtliche Blutdruck, das Ausmaß der Tagesaktivität, die Schlafeffizienz, die Melatoninausscheidung und die nächtlich produ- zierte Urinmenge hatten keinen Einfluss auf die Signifikanz dieses Befundes. Der direkte Vergleich zwischen einer Gruppe mit durchschnittlich kälterer Raumtemperatur $\left(13,2^{\circ} \mathrm{C} \pm 3,3^{\circ} \mathrm{C}\right)$ und einer Gruppe mit wärmeren Innentemperaturen $\left(18,6^{\circ} \mathrm{C} \pm 2,4^{\circ} \mathrm{C}\right)$ ergab ein signifikant häufigeres Auftreten von Nykturie bei denjenigen, die tagsüber in der Kälte lebten.

Als Grund für den vermehrten nächtlichen Harndrang vermuten Saeki und Kollegen eine kälteinduzierte Detrusorüberaktivität. Sie berechnen, dass eine Erhöhung der Innenraumtemperatur von $15,7^{\circ} \mathrm{C}$ (Durchschnittsraumtemperatur der Probanden mit Nykturie) auf $18,8^{\circ} \mathrm{C}$ die Nykturieprävalenz möglicherweise um $25 \%$ reduzieren könnte.

Insgesamt erscheinen die in Japan gemessenen Temperaturen etwas niedrig. Das deutsche Bundesumweltamt schlägt folgende Raumtemperaturen vor: „Die Raumtemperatur sollte im Wohnbereich möglichst nicht mehr als $20^{\circ} \mathrm{C}$ betragen, sofern die Temperatur als behaglich empfunden wird [...]. Unsere Empfehlung: in der Küche: $18^{\circ} \mathrm{C}$, im Schlafzimmer: $17^{\circ} \mathrm{C}$. Senken Sie die Raumtemperatur nachts oder tagsüber, wenn Sie einige Stunden lang nicht da sind, auf etwa $18^{\circ} \mathrm{C}$ ab. Bei Abwesenheit von wenigen Tagen sollte die Temperatur auf $15^{\circ} \mathrm{C}$, bei längerer Abwesenheit noch etwas niedriger eingestellt werden. Während der Nachtstunden kann die Raumtemperatur in Wohn- und Arbeitsräumen um $5^{\circ} \mathrm{C}$ gesenkt werden."

Saeki K et al. Indoor cold exposure and nocturia: a cross-sectional analysis of the HEIJO-KYO study. BJU Int 2015, online 23. September; doi: 10.1111/bju.13325

www.umweltbundesamt.de/themen/wirtschaft-konsum/umweltbewusstleben/heizenraumtemperatur 